8 The Coronary Drug Project Research Group, fournal of the American Medicul Association, 1975, 231, 360

Kannel, W. B., et al., Annals of Internal Medicine, 1971, 74, 1.

10 Norris, R. B., et al., Annals of Internal Medicine, 1971, 74, 1.77.

10 Norris, R. M., et al., New Zealand Medical fournal, 1973, 12, 77. 1975, suppl. 575 .

12 Mulcahy, R., et al., British Heart fournal, 1975, 37, 158.

13 Coronary Drug Pro;ect Research Group, fournal of Chroric Diveases, 1974, 27, 267 .

4 Wilhelmson, C., et al., Lancet, 1975, 1, 415.

15 Blackburn, H., Controversy in Internal Medicine II, ed. F. J. Ingelfinger, et al. Philadelphia, W. B. Saunders, 1974, page 162.

\section{Pseudo-obstruction of the Large Bowel}

Pseudo-obstruction is probably a bad name-there is nothing pseudo about a disorder which may kill the patient ${ }^{1}$ - but the term has passed into common clinical parlance and is unlikely to be changed. It is used to describe the condition which presents the signs and symptoms of bowel obstruction but in which exploration or further investigation shows no mechanical cause for the episode of obstruction. Acute, transient pseudoobstruction is the most common form; the aetiology is usually uncertain, but acute illnesses associated with its development include congestive cardiac failure and renal failure.

A recent report described 11 patients in detail and emphasized the important features of the condition. ${ }^{2}$ One or more of the usual signs of intestinal obstruction are often absent. Vomiting and tenderness were present in only half the patients, three had no pain, three had no constipation, and in four patients the rectum was not empty. In only five patients were the bowel sounds suggestive of mechanical obstruction; in the remaining six they were normal or decreased.

Radiological examination confirmed the presence of bowel distension, which was apparent in all 11 patients: but in only half the patients were unequivocal fluid levels present, and they were much less than would be expected with the amount of bowel distension. Sigmoidoscopy and the passage of flatus tubes have no effect on this condition.

The management of pseudo-obstruction of the large bowel is conservative, provided a firm diagnosis is made. If the diagnosis of pseudo-obstruction seems likely then an emergency barium enema is worthwhile, and it has been suggested that a dilute barium enema which demonstrates the absence of any organic obstruction may also prove to be of therapeutic value. $^{3}$ The only indication for operation is gross distension and tenderness of the caecum, suggesting that caecal rupture is a real threat. Often the diagnosis is made only at laparotomy; if no obstructing lesion is found then some form of decompression operation is probably wise, especially in those patients with considerable bowel distension. Tube caecostomy is generally the most satisfactory decompression procedure: it does not require a second procedure to close the vent, and it will certainly obviate the danger of caecal rupture.

The aetiology of pseudo-obstruction is much discussed but not understood. The site of obstruction is nearly always at the junction of a mobile and fixed part of the colon; thus the two most common points are the left side of the transverse colon and the rectosigmoid junction. Possibly some degree of bowel distension causes kinking at the point of fixation, and this "hinge-kink" mechanism may become self-perpetuating and cause a mechanical valvular obstruction. However, the change in bowel calibre is not always abrupt, and in the present series there were several patients in whom the lumen of the colon was noted to taper down to normal over a considerable length. Other theories include abnormalities of colonic motility, which may be produced by alterations in blood flow, perhaps as the result of distension or anoxia; very rarely malignant infiltration of the autonomic nerves on the posterior abdominal wall may be so gross as to produce neurogenic obstruction.

1 Melamed, M., and Kubian, E., Radiology, 1963, 80, 22.

2 Bardsley, D., British Fournal of Surgery, 1974, 61, 963.

3 Dudley, H. A. F., et al., Fournal of the Royal College of Surgeons of Edinburgh, 1958, 3, 206.

\section{Rats Today}

Probably $10 \%$ of the world's food supply is consumed or damaged by rats: rice in the East, sugar cane in the West Indies, and flour in Liverpool warehouses. Rats will even eat the grease on the railway points on London's Underground. These vermin are everywhere, so it is little wonder that most strong poisons have been used at one time or another to kill them. In warehouses and ships which can be sealed up during disinfestation the results are uniformly good, but elsewhere ordinary poisons may be highly dangerous to human beings and domestic livestock. In open places where food is at risk cats have always played an important part in rat controleven the Port of London Authority regarded the small milk bill incurred for cats as one of its most rewarding expenses. It may indeed be argued that recent legislation prohibiting cats in food shops and similar places may have been mistaken, as may the prohibition of gin traps on farms, at a time when the British rat population is increasing. The cat sitting on top of a sugar sack in a grocer's shop may be unhygienic, but there is far greater danger to the public health from resident rodents.

Rats no longer transmit plague in Britain (they still could do so), but they cause a disquieting number of spirochaetal infections both in man and animals. It is not always realized that many of these animal infections are communicable to man in addition to the well-known Weil's disease and rat-bite fever. The quite dramatic improvement in the state of health of a pack of hounds once a rat infestation and leptospirosis was eliminated from the kennels was shown recently. ${ }^{1}$ Half the rats in this country are believed to carry some variety of spirochaete.

At the time when the anticoagulant warfarin came into general use over 10 years ago, it was hoped that at last a selective rat poison had arrived, since ordinary domestic animals, with the exception of pigs, are not particularly sensitive to it. (Pigs will eat rats dead from warfarin and may suffer in consequence.) As usually happens in nature after prolonged exposure to toxic substances, resistance developed. What were regarded initially as pockets of resistance have spread to the rat population generally, thus indicating the need for yet another rodenticide.

A small quantity of vitamin $\mathrm{D}$ (calciferol) is an essential mammalian dietary requirement, and any deficiency results in low calcium blood levels. Conversely a gross excess of calciferol produces dangerously high calcium levels, and this action provides the basis for a new way of attacking warfarinresistant rat populations. Warfarin acts by blocking vitamin $\mathrm{K}$ metabolism, thereby inhibiting blood clotting; so by giving rats warfarin and calciferol together they die from the effects of too little vitamin $\mathrm{K}$ and too much vitamin $\mathrm{D}$. Here it is 
worth mentioning the remarkable behaviour of rats exposed to warfarin alone on certain East Anglian farms: they seek out marram grass on the sand dunes, since it has a naturally high content of vitamin $\mathrm{K}$.

The potential of calciferol as a rodenticide have recently been studied by Greaves et al. ${ }^{2}$ They found that in experimental conditions nearly all animals fed on $0.1 \%$ of this vitamin were dead in two days. Resistance to warfarin in $R$. norvegicus may be correlated with susceptibility to calciferol, and further studies on mixtures of calciferol and warfarin showed that there was an additive effect between the components.

Field trials made by Rennison ${ }^{3}$ confirmed that $0.1 \%$ calciferol, alone or combined with warfarin, was an effective poison for warfarin-resistant rats; however, the technique needed to obtain the best results may present difficulties in the hurly-burly of wide-scale usage. Other unpublished field trials have produced rather variable and not easily explained results, though it is generally agreed that the new combined preparation, despite the care needed in its application, always justifies a trial for infestations known to be warfarinresistant. Fortunately when all else fails we can still fall back on highly lethal compounds likezinc phosphide and fluoracetamide, but they must be applied circumspectly.

\footnotetext{
1 Thrower, W. R., Transactions of the Medical Society of London, 1971, 87,

2 Greaves, J. H., Redfern, R., and King, R. E., fournal of Hygiene, 1974, 73,

341.
3 Remison, B. D., fournal of Hygiene, 1974, 73, 361.
}

\section{Fish Farms and Botulism}

Botulism is a horrific disease; by the successive involvement of cranial nerves it deprives its victim of sight, speech, and the power to swallow, and unless in a respirator he will die of asphyxia because eventually unable to breathe. Though mercifully very rare it is consequently dreaded, and a nightmare in the canning industry, since inadequate processing of a single batch of some food may cause it in the consumer. It is an intoxication, the toxin being formed under anaerobic conditions in food containing living spores of Clostridium botulinum, an organism fairly widely distributed in soil. Meat products and particularly home-canned vegetables are commonly responsible, but fish is another source, notably in countries bordering the northern Pacific Ocean, Canada, Alaska, and Japan. In that region the organism, almost always of type E, exists in the silt on the sea bottom and is swallowed by fish and may be found in their gut contents. The bacterium has no effect on the fish, but it may contaminate fish products-often eaten uncooked, and in forms sounding somewhat unsavoury, in these areas.

Though much less common elsewhere, fish botulism is not entirely confined to the northern Pacific shores. In a communication to a symposium held in Moscow in $1966^{1}$ Cann et al. of the Torry Research Station, Aberdeen, reported a study of the distribution of $\mathrm{Cl}$. botulinum type $\mathrm{E}$ on both sides of the North Sea in herring and white fish and in deposits on the sea bed. Samples of bottom deposit from the neighbourhood of Aberdeen and fish landed from British fishing grounds were uniformly negative, but herrings caught in Norwegian waters and bottom deposits from the Skaggerak and Kattegat gave about $50 \%$ of positive isolations.

Fish farming is a new and rapidly expanding industry, and it is natural to inquire what risk it may entail of yielding contaminated fish products. Burns and Williams ${ }^{2}$ of the Highland Health Board studied three farms, two of which had concrete "raceways", one taking fresh water from a loch and the other a mixture of fresh water and sea water, and a third was a "mud farm", in which water from a stream passed through a presumably natural channel. Trout of marketable size were netted from each and mud was collected from the bottoms of all the tanks; these were all examined for the presence of $\mathrm{Cl}$. botulinum. All specimens from the first two farms were negative, but the organism was found in 1 out of 21 fish from the third farm and in 9 out of 37 samples of mud from it (the numbers of mud samples from the first two were only 5 and 2). All the organisms were of type B. This is perhaps not surprising, since type $B$ is the commonest found in European soils and this farm was supplied with fresh water; type $\mathrm{E}$ is found mainly in a marine environment.

There is, then, a risk of contamination in fish raised in natural water channels with mud bottoms; whether these present any advantage-or drawback-except presumably the lesser cost of establishing them these authors do not discuss. $\mathrm{Cl}$. botulinum type $\mathrm{E}$ was found in German fish farms after the deaths of three consumers of vacuum-packed smoked trout fillets. This type of packaging (if it merits its description) should secure anaerobiosis just as well as canning, and such products should perhaps be viewed with suspicion, unless they have been sterilized. High energy irradiation is presumably a possibility for this, though perhaps not commercially feasible. Another possible safeguard is efficient smoking. Consumers of smoked salmon, the most popular form of raw fish in many countries, may find some reassurance in the work of Nielson and Pederson ${ }^{3}$ of Denmark, who studied the effect of smoke constituents on the germination of $\mathrm{Cl}$. botulinum spores artificially introduced into slices of the flesh of salmon from the Baltic. They say nothing about essential oils, which might be thought the main bactericidal constituent in smoke, but tested the effects of phenols, which failed to prevent spore germination, and of formaldehyde, which they found in a concentration of 20-40 $\mu \mathrm{g}$ per gram of smoked salmon, and showed this to be effective in short term experiments. What sort of smoke was produced to yield this constituent-incidentally a prohibited food additive-was not revealed. A smoked salmon exposed in the usual way to the atmosphere should almost certainly be safe anyhow.

${ }^{1}$ Cann, D., et al., in Botulism 1966. Proceedings of the Fifth International Symposium on Food Microbiology, ed. M. Ingram and T. A. Roberts. London, Chapman and Hall, 1967, p. 62.

2 Burns, G. F., and Williams, H., Fournal of Hygiene, 1975, 74, 1.

3 Nielson, S. F., and Pedersen, H. O., in Botulism 1966. Proceedings of the Fifth International Symposium on Food Microbiology, ed. M. Ingram and T. A. Roberts. London, Chapman and Hall, 1967, p. 66.

\section{Of Moles and Malignancy}

The mole that could be malignant is a common problem for general practitioners. It may first be noticed during a medical examination, or the patient's alarm may be triggered off perhaps by a magazine article or by a recent death in the family from cancer.

Since most such lesions prove benign an attitude of optimism is sound, but in an individual patient it may be far from easy for the general practitioner (or the dermatologist) to be certain on clinical grounds of the type of lesion, let alone 